\title{
Awareness of Awkward Posture and Repetitive Motion as Ergonomic Factors Associated With Musculoskeletal Disorders by Health Promotion Professionals
}

\author{
Uchechukwu A. Ezugwu ${ }^{1}$, Elom N. Egba ${ }^{2}$, Paulinus C. Igweagu ${ }^{3}$, Lazarus E. Eneje ${ }^{4}$, \\ Scholastica Orji ${ }^{2}$ \& Uchenna C. Ugwu \\ ${ }^{1}$ Department of Medical Rehabilitation, Faculty of Health Science and Technology, University of Nigeria, Enugu \\ Campus, Nigeria \\ ${ }^{2}$ Department of Human Kinetics and Health Education, Faculty of Eduucation, Ebonyi State University, Abakaliki, \\ Ebonyi State, Nigeria \\ ${ }^{3}$ Department of Community Medicine, Enugu State University of Science and Technology, Enugu State, Nigeria \\ ${ }^{4}$ School of Health Technology, Oji-River, Enugu State, Nigeria \\ ${ }^{5}$ Department of Human Kinetics and Health Education, Faculty of Eduucation, University of Nigeria, Nsukka, \\ Enugu State, Nigeria \\ Correspondence: Paulinus C. Igweagu, Department of Community Medicine, Enugu State University of Science \\ and Technology, Enugu State, Nigeria. Tel: 234-803-407-5753. E-mail: cpigweagu@yahoo.com
}

Received: March 16, 2020 Accepted: April 11, 2020 Online Published: April 27, 2020

doi:10.5539/gjhs.v12n6p128 URL: https://doi.org/10.5539/gjhs.v12n6p128

\begin{abstract}
Musculoskeletal disorders -MSD, particularly on the muscles, tendons, ligaments, joints and cartilage decline the general physiological efficiency of the human body systems. The study aimed to ascertain the status of awareness of awkward posture and repetitive motion as ergonomic factors associated with MSD by health promotion professionals -HPP. The study adopted descriptive survey approach and was carried out in Enugu State of Nigeria, from August 2019 to February 2020. The participants were experts in health promotion through physical exercises. A well-structured questionnaire with reliability index of 0.86 was the only instrument used for data collection. The data analysis was completed using SPSS version 21. All the participants were Nigerians totaling 323 and responded to the questionnaire items completely and correctly. Majority of them were: females 196(60.7\%) and rural dwellers $183(56.7 \%)$. The study revealed that the health promotion professionals were aware of awkward posture $(\mathrm{M}=3.22 ; \mathrm{SD}=0.80)$ and repetitive motion $(\mathrm{M}=3.18 ; \mathrm{SD}=0.79)$ as ergonomic factors associated with MSD. The status of awareness of the study phenomenon varied within variables of gender and location. A statistically significant difference was observed with regards to location $(\mathrm{P}$-value $<0.05$ ) while none existed on gender ( $P$-value $>0.05)$. Although, the awareness status varied within variables, there is clear demonstration that the status of awareness regarding awkward posture and repetitive motion as ergonomic factors associated with MSD was encouraging. This translates the actual application of the rehabilitative and remedial measures in health promoting exercises involved in improving the quality of life and wellness. Indeed, there is need for routine workshops, seminars and conferences organized for these professionals on addressing ergonomic factors associated with MSD.
\end{abstract}

Keywords: ergonomic factors, posture, MSD, motion, HPPs

\section{Introduction}

Worldwide, musculoskeletal disorder -MSD declines the physiological efficiency of the human body systems (Hsin-Yi, Man-Ting, Yu-Chung, \& Yan-Ying, 2016). This situation has placed MSD as a major public health problem in both developed and developing countries. Statistically, about 91 per cent of workers in the United Kingdom are affected by musculoskeletal disorders (Glover, McGregor, Sullivan, \& Hague, 2005). In Australia, approximately 85 per cent were reported (Cromue, Robertson, \& Best, 2000) while Nigeria is estimated at 91.3 per cent (Babatunde, Ashiya, \& Adewale, 2008). These statistics are indications that Nigeria has the highest percentage prevalence of MSDs. Contextually, MSD is considered as injury or disorder of the soft tissues 
(examples are muscles, tendons, ligaments, joints and cartilage) as well as nervous systems (Anita, Yazdan, \& Hayati, 2014). It could also be seen as damage or pain occurring in the musculoskeletal system arising from a sudden exertion (like lifting a heavy object), or making the same motion repeatedly, repetitive strain, or from repeated exposure to force, vibration, or awkward posture (Center for Disease control and Prevention, 2016a; 2016b). Previously, the Occupational Safety and Health Administration (OSHA, 2007) indicated that ergonomic factors such as awkward posture, repetitive position, vibration and force of movement were associated with MSDs. However, the scientific discipline concerned with the understanding of interactions among humans and other elements of a system is seen as ergonomics (International Ergonomic Association -IEA, 2006; Ismaila, 2010). Literarily, ergonomic factors are physical factors (awkward posture and repetitive motion) of any source or situation with the potential to cause injury or lead to the development of a disease as a worker carries out his/her duty in the workplace (NIOSH, 2007; Occupational Safety and Health Administration, 2007). Awkward posture is the deviation of the body from its natural or neutral position while job tasks are being performed which may include reaching behind, twisting, working ahead, wrist-bending, kneeling, stooping and squatting (National Institute for Occupational Safety -NIOSH, 1997; NIOSH, 2007; OSHA, 2007; Nunes, 2009). On the other hand, repetitive motion disorders are muscular conditions that result from repeated motions performed in the course of doing normal work or carrying out daily activities (Franklin, Ingrid, Susan \& Barbara, 2006; Shakya \& Shrestha, 2018).Workers performing repetitive movements are at higher risk of developing disorders such as trigger finger, carpal tunnels syndone, bursitis, tendonitis, epicondylitis, ganglion cyst, and tenosynovities (NIOSH, 2007). The above scenario formed part of the motivation to carry out this study using the health promotion professionals in developing country -Nigeria and its subsetting -Enugu State. The HPPs are the most appropriate group for effective and well-programmed health promoting exercises and thus making their level of awareness about the ergonomic factors associated with musculoskeletal disorders indispensible for proper rehabilitation and correction of postural defects and subsequently improving the quality of health of individuals. Therefore, this study was set to ascetain the status of awareness of awkward posture and repetitive motion as ergonomic factors associated with musculoskeletal disorders by health promotion professionals and also to verify the null hypotheses of no significant difference within variables. As one of the expectations of the researchers, the outcome of this research would form the basis for designing programmes or formulating appropriate health promoting strategies that would address multiple ergonomic factors associated with musculoskeletal disorders in human population. At present, this study remains the first of its kind in Enugu State of Nigeria. Specifically, the study seeks to ascertain:

1) The status of awareness of awkward posture and repetitive motion as ergonomic factors associated with musculoskeletal disorders by health promotion professionals.

2) The status of awareness of awkward posture and repetitive motion as ergonomic factors associated with musculoskeletal disorders by health promotion professionals based on socio-demographics.

\subsection{Research Questions}

The study was guided by the following research questions:

1) What is the status of awareness of awkward posture and repetive motion as ergonomic factors associated with musculoskeletal disorders by health promotion professionals?

2) What are the status of awareness of awkward posture and repetitive motion as ergonomic factors associated with musculoskeletal disorders by health promotion professionals based on socio-demographics?

\subsection{Hypotheses}

The following postulated null hypotheses guided the research and were tested at .05 level of significance at appropriate degree of freedom.

$\mathrm{H}_{1}$ : There is no statistically significant difference in the status of awareness of awkward posture and repetitive motion as ergonomic factors associated with musculoskeletal disorders by health promotion professionals based on gender.

$\mathrm{HO}_{2}$ : There is no statistically significant difference in the status of awareness of awkward posture and repetitive motion as ergonomic factors associated with musculoskeletal disorders by health promotion professionals based on location.

\section{Method}

\subsection{Design and Participants}

The study adopted descriptive survey approach and was carried out in Enugu State of Nigeria, from August 2019 to 
February 2020 (National Population Commission, 2019). The participants were experts in health promotion through physical exercises. A total of 323 participants was anonymously sampled and studied. This sample size was calculated using 95 per cent confidence level and 5 per cent confidence interval (Cohen, Manion \& Morrison, 2011). The eligibility criteria used for the study involved all the experts in health promotion who adopt physical exercises in accomplishing specified health promoting goal. These individuals include: health and physical educators, medical rehabilitator, human kinesiologists, medical restorators, to be mentioned but a few. These set of experts were chosen due to their broader knowledge and understanding of posture, motion, ergonomic factors and musculoskeletal disorders in human body systems. All the health professionals who do not consider physical exercises as integral part of their professional roles in health promotion were excluded in the study.

\subsection{Settings}

The study was conducted in Enugu State, which is one of the five states that constitute the southeastern geopolitical zone of the country. The state is highly organized with a good number of functional healthcare facilities and educational institutions that serve as avenue for the training and modeling of experts and professionals in the areas of health promotion and disease control as well as preventions. Usually, these professionals are gainfully employed in the diverse establishements within and outside the state where they successfully render professional and quality health promoting services to clients and patients. Prior to the actual data collection, the researchers gave a formal introduction of the study and also obtain informed consent from all the prospective participants.

\subsection{Instrument}

A well-structured questionnaire with reliability index of 0.86 was the only instrument used for data collection. The instrument was written in English language and was organized in different sections to reflect the socio-demogrphic variables of the participants and the status of awareness of the study phenomenon. The questionnaire items were arranged to generate responses from the study participants without any bias. The actual administration and distribution of the questionnaire to all the participants was successfully carried out the researchers.

\subsection{Data Analysis}

The study generated quantitative data. The data analysis was completed using SPSS version 21 . The criterion mean value of 2.50 accrued from the four-point response options was used for decision, that is to say, any item that weighs 2.50 and above implies high or being aware while any item less than 2.50 signifies low or unaware. The hypothesis was accepted when the p-value is greater than 0.05 and rejected when the p-value is below 0.05 .

\subsection{Ethical Statement}

The ethical approval for the study was obtained from the Faculty of Education Research Grants Committee, University of Nigeria Nsukka [Ethical approval code: ERA.058]. This is one of the Institutional Review Board Committees of the University of Nigeria that gives approval for studies of this kind and also in accordance with the principles of the Declaration of Helsinki (World Medical Association, 2013). The participants' confidentiality and interest were guaranteed. Also, no payement or financial commitment was made to the participants for responding to the items of the questionnaire. The study was free from all forms of physical, social and envriomental harm or hazard due to the fact that the data collection process primarily relied on a descriptive non-invasive questionnaire.

\section{Results}

Table 1. Socio-demographic profile of the participants $(\mathrm{N}=323)$

\begin{tabular}{llll}
\hline Socio-demographics & $\mathrm{f}$ & {$[\%]$} & \\
\hline Gender & Male & 127 & {$[39.3]$} \\
& Female & 196 & {$[60.7]$} \\
\hline Location & Urban & 140 & {$[43.3]$} \\
& Rural & 183 & {$[56.7]$} \\
\hline
\end{tabular}

Keys: $f=$ frequency, $\%=$ per cent,$N=$ sample size.

All the participants were Nigerians totaling 323 and also responded to the questionnaire items completely and correctly. Majority of them were: females $196(60.7 \%)$ and rural dwellers $183(56.7 \%)$ while only few of them were males $127(39.3 \%)$ and urban settlers (43.3\%) (see Table 1). 
Table 2. Showing participants' awareness of awkward posture and repetitive motion as ergonomic factors associated with MSD $(\mathrm{N}=323)$

\begin{tabular}{lll}
\hline Ergonomic Factors & $\mathrm{M} \pm \mathrm{SD}$ & Dec \\
\hline Awareness of awkward Posture & $3.22 \pm 0.80$ & Aware \\
Awareness of repetitive motion & $3.18 \pm 0.79$ & Aware \\
\hline
\end{tabular}

Keys: $M=$ mean value; $S D=$ standard deviation; $N=$ sample size.

The outcome of data in this table revealed that the health promotion professionals were aware of awkward posture $(\mathrm{M}=3.22 ; \mathrm{SD}=0.80)$ and repetitive motion $(\mathrm{M}=3.18 ; \mathrm{SD}=0.79)$ as ergonomic factors associated with musculoskeletal disorders. (see Table 2).

Table 3. Presenting sociodemographic variations and statistically significant differences within variables on the status of awareness of the study phenomenon $(\mathrm{N}=323)$

\begin{tabular}{|c|c|c|c|c|c|c|c|}
\hline \multirow{2}{*}{$\begin{array}{l}\text { Parameters } \\
\text { Variables }\end{array}$} & \multicolumn{3}{|c|}{ Ergonomic factors } & \multirow[t]{2}{*}{ Status } & \multirow[t]{2}{*}{ t-cal } & \multirow[t]{2}{*}{ P-value } & \multirow[t]{2}{*}{ Remarks } \\
\hline & & $\mathrm{N}$ & $\mathrm{M} \pm \mathrm{SD}$ & & & & \\
\hline \multirow[t]{2}{*}{ Gender } & Male & 127 & $3.23 \pm 0.36$ & Aware & 0.412 & $0.681>0.05$ & Accepted \\
\hline & Female & 196 & $3.21 \pm 0.32$ & Aware & & & \\
\hline \multirow[t]{2}{*}{ Location } & Urban & 140 & $3.37 \pm 0.30$ & Aware & 7.765 & $0.000<0.05$ & Rejected \\
\hline & Rural & 183 & $3.10 \pm 0.31$ & Aware & & & \\
\hline
\end{tabular}

The socio-demographic variations and statistically significant differences on the awareness of awkward posture and repetitive motion as ergonomic factors associated with musculoskeletal disorders were presented. As shown in the Table, all the participants irrespective of socio-demographic differences were aware of awkward posture and repetitive motion as ergonomic factors associated with MSD. Although, the awareness levels were higher among male participants $(\mathrm{M}=3.23, \mathrm{SD}=0.36)$ and those in urban settings $(\mathrm{M}=3.10, \mathrm{SD}=0.31)$ when compared with their female $(\mathrm{M}=3.21, \mathrm{SD}=0.32)$ and rural $(\mathrm{M}=3.10, \mathrm{SD}=0.31)$ counterparts. A statistically significant difference was observed with regards to location $(\mathrm{P}=0.000<0.05)$ while none existed on gender $(\mathrm{P}=0.681>0.05)$.

\section{Discussion}

This present study is currently the first descriptive survey to establish the awareness status of awkward posture and repetitive motion as ergonomic factors associated with musculoskeletal disorders by health promotion professionals in Enugu State of Nigeria. The finding of the study which indicated high awareness regarding the study phenomenon is quite encouraging. This is because it could form the basis for designing programmes or formulating appropriate health promoting strategies that would be useful in addressing awkward posture and repetitive motion that contribute to musculoskeletal disorders. Mohan, Justine, Jagannathan, Aminudin, and Johari (2015) found that physical factors such as prolonged standing, sitting, and uncomfortable posture are known to be associated with MSD. Of all the participants studied, a greater percentage of them were females $(60.7 \%)$ and rural dwellers (56.7\%). This finding is surprising as it clearly demonstrates that the socio-demographic variations are not hinderance to the awareness status of the participants. Also, it could signify that irrespective of gender and location, all the HPPs have greater passion and interest in addressing ergonomic factors associated with musculoskeletal disorders.

The result of the present study is in consistence with other report findings. For instance, in descriptive survey involving a sample of nursery school teachers, it was reported that the participants performed wide variety of tasks with the combination of basic health, child health, teaching duties and works that require mechanical loads and trunk flexion (Chong \& Chan, 2010). Similarly, Bogaeret et al., (2015) reported that awkward postures such as long periods of standing and standing with bended backs for several hours of teaching were associated with the risk of musculoskeletal disorders. Furthermore, other researchers observed that sustained awkward seating posture (lordosed or kyphosed, overly arched, or slouched) can result in higher intradiscal pressure and may be injurious to spinal postural health (Pynt et al., 2002). In our study, the male participants as well as the urban dwellers indicated higher awareness of the study phenomenon more than their counterparts. These findings are interesting and 
demonstrate that the level of awareness regarding a given phenomenon can be influenced by certain socio-demographics.

The present outcome of this study is in consistence with the findings of other researchers who reported that demographic variables influenced greatly the outcomes of their researches in varying perspectives (Fjellman-Wiklund, Brulin, \& Sundelin, 2003; Treaster \& Burr, 2004; Joshi \& Chopra, 2009; Cardoso, Queiroz, Maria, Carvalho, \& Jose, 2009; Nordander et al., 2010; Patience \& Derek, 2014; Solis-Soto, Schon, Solis-Soto, Parra, \& Radon, 2017). Specifically, Erick and Smith (2011) reported a higher prevalence of neck and back, upper and lower limbs complaint among females than male counterparts. Also, there was also a significant higher prevalence of MSDs among females compared to males between school teachers in Botswana (Erick \& Smith, 2014). In Poland, El-Gendy and Korish (2017) found that the prevalence of MSDs was higher among females than the male counterparts. Also, Patience and Derek (2014) revealed that female gender was associated with the development of musculoskeletal disorders (low back pain (LBP) and disability). Furthermore, Solis-Soto, Schon, Solis-Soto, Parra, and Radon (2017) found that differences existed in the awkward posture among teachers working in rural areas and those in the urban settings.

A statistically significant difference was observed with regards to location while none existed on gender. This finding is parallel to study conducted by other researchers which showed significant interference within socio-demographic variables in their studies (Patience \& Derek, 2014; Solis-Soto, Schon, Solis-Soto, Parra \& Radon, 2017). In application, the findings of the current research would be crucial in designing educational program on ergonomic factors and musculoskeletal disorders with maximum consideration of socio-demographic variations. This could be linked with other similar reports. It has earlier been reported that most work-related musculoskeletal disorders develop over time due to repetitive motion are caused by either work itself or by the employee's working environment (Punnett, Gold, Katz, Gore, \& Wegman, 2004). In a different perspective, other researchers indicated that workers performing repetitive movements are at a high risk of developing disorders because of strain on tendons and ligaments and the reduced recovery time between movements (NIOSH, 2007). In 2016, a study on work-related musculoskeletal disorders and ergonomic risk factors among special education teachers and teacher's aides revealed that the lower back, shoulder, and wrist were the three most affected regions due to repetitive movements (Hsin-Yi, Man-Ting, Yu-Chung, \& Yan-Ying, 2016).

The strength of this descriptive survey study lies in its methodology and target population (health promotion professionals) as well as the key concepts under investigation. However, there is still obvious limitation of our study. The outcome of the present study will not be generalized to the larger population of health promotion professionals worldwide since the scope was delimited to Enugu State of Nigeria. Hence, there is need to carry out similar study in other states of the federation as well as other countries of the world other than Nigeria. Finally, further study is need to incorporate more socio-demographic variables such as years of working experience, educational qualification, religious affiliation and marital status. Such study would avail data and further fill the obvious research gap of this nature.

\section{Conclusion}

Although, the awareness status varied within variables, there is clear demonstration that the status of awareness regarding awkward posture and repetitive motion as ergonomic factors associated with MSD was encouraging. This translates the actual application of the rehabilitative and remedial measures in health promoting exercises involved in improving the quality of life and wellness. Indeed, there is need for routine workshops, seminars and conferences organized for these professionals on addressing ergonomic factors associated with MSD.

\section{Acknowledgments}

None to declare.

\section{Contributions by Authors}

UAC and ENE initiated the title and sourced for relevant literature. UCU and PCI wrote the manuscript. LEE and UCU analyzed and interpreted the data. All the authors contributed to the study concept and design, acquisition of subjects and manuscript review. UCU and SO drafted the manuscript and revising it critically for important intellectual content. All authors have read and approved the final version of the manuscript.

\section{Competing Interests Statement}

The authors declare that there are no competing or potential conflicts of interest.

\section{References}

Anita, A. R., Yazdan, A., \& Hayati, K. S. (2014). Association between awkward posture and musculoskeletal 
disorders among assembly line workers in an automotive industry. Journal of Medicine and Health Science, 10(1), 34-46.

Babatunde, A., Ashiya, A., \& Adewale, O. (2008). Work-related musculoskeletal disorders among Nigeria physiotherapists.BMC Musculoskeletal Disorders, 9, 112. https://doi.org/10.1186/1471-2474-9-112

Bogaert, I., Martelaer, K., Beutels, M., Ridder, K., \& Zinzen, E. (2016). Posture analysis among Flemish secondary school teachers: difference between the use of chalkboards and electronic school boards during classroom teaching. Ergonomics, 59(11), 1487-1493. https://doi.org/10.1080/00140139.2016.1139751

Cardoso, J. P., De Queiroz, B. R., Maria, A. T., Carvalho, F. M., \& José, F. B. (2009). Prevalence of musculoskeletal pain among teachers. Revista Brasileira de Epidemiologia, 12(4), 1-10.

Center for Disease Control and Prevention (CDC). (2016b). NIOSH publications and products-musculoskeletal disorders and workplace factors. Retrieved on 2019-12-14 from www.cdc.gov

Center for Disease Control and Prevention (CDC). (2016a). NIOSH program portfolio: musculoskeletal disorders: program description. Retrieved on 2019-12-02 from .www.cdc.gov.

Chong, E. Y., \& Chan, A. H. (2010). Subjective health complaints of teachers from primary and secondary schools in Hong Kong. International Journal of Occupation Safety Ergonomics, 16(1), 23-39. https://doi.org/10.1080/10803548.2010.11076825

Cohen, L., Manion, L., \& Morrison, K. (2011). Research methods in education (7th ed.). New York: Routledge Taylor \& Francis Group.

Cromue, J. E., Robberton, V. J., \& Best, M. O. (2000). Work-related musculoskeletal disorders in physical thereapists: prevalence, severity, risks and responses. Public Medicine, 80(4), 336-351. https://doi.org/10.1093/ptj/80.4.336

El -Gendy, M., \& Korish, M. M. (2017). Work related musculoskeletal disorders among preparatory school Teachers in Egypt. Egyptian Journal of Occupational Medicine, 41(1), $115-126$. https://doi.org/10.21608/ejom.2017.965

Erick, P. N., \& Smith, D. R. (2011). A systematic review of musculoskeletal disorders among school teachers. BMC Musculoskeletal Disorders, 12(1), 260. https://doi.org/10.1186/1471-2474-12-260

Erick, P. N., \& Smith, D. R. (2014). The prevalence and risk factors for musculoskeletal disorders among school teachers in Botswana. Occupational Medicine Health Aff., 2, 4. https://doi.org/10.4172/2329-6879.1000178

Fjellman-Wiklund, A., Brulin, C., \& Sundelin, G. (2003). Physical and psychosocial work-related risk factors associated with neck-shoulder discomfort in male and female music teachers. Medical Problems of Performing Artists, 18, 33-41.

Franklin, S., Ingrid, S., Susan, C., \& Barbara, L. (2006). Textbook of occupational therapy and ergonomics. Amazon.

Glover, W., McGregor, A., Sullivan, C., \& Hague, J. (2005). Work-related musculoskeletal disorders affecting members of the chartered society of physiotherapy. Physiotherapy, 91, 138-147. https://doi.org/10.1016/j.physio.2005.06.001

Hsin-Yi, K. C., Man-Ting, W., Yu-Chung, Y., \& Yan-Ying, J. (2016). Work-related musculoskeletal disorders and ergonomic risk factors in special education teachers and teacher's aides. BMC Public Health, 16(7), $27-77$. https://doi.org/10.1186/s12889-016-2777-7

International Ergonomic Association (IEA). (2006). Karwowski. https://doi.org/10.1201/9780849375477Ch29

Ismaila, S. O. (2010). A study on ergonomics awareness in Nigeria. Austrian Journal of Basic Applied Science, 4,731-734.

Mohan, V., Justine, M., Jagannathan, M., Aminudin, S., \& Johari, S. H. (2015). Preliminary study of the patterns and physical risk factors of work-related musculoskeletal disorders among academicians in a higher learning institute. Journal of Orthop Science, 6(5), 65-73. https://doi.org/10.1007/s00776-014-0682-4

National Institute for Occupational Safety (NIOSH). (1997). Mmusculoskeletal disorders and workplace factors: A critical review of epidemiologic evidence for work-related musculoskeletal disorders of the neck upper extremity and low back. Cincinnati: US Department of Health and Human Services. 
National Institute for Occupational Safety (NIOSH). (2007). Criteria for a recommended standard: Occupational Exposure to Hand-Arm Vibration. US Department of Health and Human Services. Pub. No. 89-106.

National Population Commission. Office of the presidency. Nigeria (2019). Research and Statistics Unit, NUP, Federal Capital Territory Abuja.

Nordander, C., Ohlsson, K., Akesson, I., Arvidsson, I., Balogh, I., Hansson, G. A., \& Skerfving, S. (2010). Risk of musculoskeletal disorders among females and males in repetitive/constrained work. Ergonomics, 52(10), 1226-1239. https://doi.org/10.1080/00140130903056071

Nunes, I. L. (2009). FAST ERGO_X- a tool for ergonomic auditing and work-related musculoskeletal disorders prevention. Work, 34(2), 133-148. https://doi.org/10.3233/WOR-2009-0912

Occupational Safety and Health Administration (OSHA). (2007). Ergonomics: The study of work. Retrieved on 15/12/2019 from: http://www.washingtonpost.com/wpsr/buiness/legacy/pdf/ergonomic_study_of_workpdf.

Punnett, L., Gold J., Katz, J. N., Gore, R., \& Wegman, D. H. (2004). Ergonomic stressors and upper extremity musculoskeletal disorders in automobile manufacturing: a one year follow-up study. Occupational and Environmental Medicine, 61(8), 668-674. https://doi.org/10.1136/oem.2003.008979

Pynt, J., Higgs, J., \& Mackey, M. (2002). Milestones in the evolution of lumbar spinal postural health in seating. Spine, 27(19), 2180-2189. https://doi.org/10.1097/00007632-200210010-00020

Shakya, N., \& Shrestha, S. (2018). Prevalence of work related musculoskeletal disorders among Canteen staff of Kathmandu University. Journal of Kathmandu Medical College, 7(4), 162-167. https://doi.org/10.3126/jkmc.v7i4.23318

Solis-Soto, M. T., Schon, A., Solis-Soto, A., Parra, M., \& Radon, K. (2017). Prevalence of musculoskeletal disorders among school teachers from urban and rural areas in Chuquisaca, Bolivia. BMC Musculoskeletal Disorder, 18, 425. https://doi.org/10.1186/s12891-017-1785-9

Treaster, D., \& Burr, D. (2004). Gender differences in prevalence of upper extremity musculoskeletal disorders. Ergonomics, 47(5), 495-526. https://doi.org/10.1080/00140130310001638171

World Medical Association. (2013). Declaration of Helsinki Ethical Principles for Medical Research Involving Human Subjects. JAMA, 310, 2191-2194. https://doi.org/10.1001/jama.2013.281053

\section{Copyrights}

Copyright for this article is retained by the author(s), with first publication rights granted to the journal.

This is an open-access article distributed under the terms and conditions of the Creative Commons Attribution license (http://creativecommons.org/licenses/by/4.0/). 